\title{
Impact of flexible bioenergy provision on residual load fluctuation: a case study for the TransnetBW transmission system
} in 2022

Philip Tafarte ${ }^{1 *}$, Christiane Hennig ${ }^{2}$, Martin Dotzauer ${ }^{2}$ and Daniela Thrän ${ }^{1,2}$

\begin{abstract}
Background: The transition towards a renewable based power system in Germany largely depends on variable renewable energy sources (vRES) like wind power and solar PV. Their high variability over time poses new challenges for power system stability. Bioenergy as a renewable source has already been established in recent years and has the capability to offset fluctuations from wind and solar PV and can therefore play a new role in coming years.

Methods: This paper describes how existing bioenergy plants can be operated in order to offset fluctuations in power systems, performing a power system modelling based on time series data. As sample transmission system (TS), TransnetBW has been chosen, one of the four German transmission systems. We modelled two different types of bioenergy plant clusters, one including solid biomass plants and the other cluster covering biogas plants and other plants with comparable characteristics. For the modelling of the operation of these clusters, we used registered time series of the years 2011 and 2012 for a total load and feed-in from wind and solar PV, which were projected for the year 2022. The flexible bioenergy clusters are operated in order to minimize fluctuations in residual load (RL). This approach served as the basis to assess how concepts for flexible bioenergy provision can contribute to the task of balancing future power systems based on vRES.

Results: Bioenergy plays an important role in the renewable power supply of the TransnetBW TS, as it holds a share of 23.3\% among the renewables projected for 2022. A flexible bioenergy (BE) provision allows for a reduction in daily residual load fluctuations by $30 \%$ compared to the non-flexible power generation from BE. Flexible BE effectively offsets high fluctuations originated from the feed-in of the substantial solar PV installations in the TS and also contributes to serve the peak load. But in contrast to regions with higher renewable shares from vRES, the amount of avoided BE power production in times of negative RL (excess power from renewables) is still negligible for the 2022 time frame investigated and thus reducing the immanent requirement for flexible BE. (Continued on next page)
\end{abstract}

\footnotetext{
*Correspondence: philip.tafarte@ufz.de

${ }^{1}$ Helmholtz Centre for Environmental Research - UFZ, Permoser Straße 15,

04318 Leipzig, Germany

Full list of author information is available at the end of the article
} 
(Continued from previous page)

Conclusions: In line with existing studies, the results show that bioenergy is already a valuable asset to achieve the targeted REN shares and can support the integration of the large vRES capacities in coming years, if produced flexibly. Operating biomass installations in a flexible manner effectively reduce daily fluctuations in RL, allow for a better integration of vRES and contribute to cover peak power demand. But from the findings of this case study, we conclude that the focus in the near-term should be on the efficient utilization of BE as the top priority until the demand for flexible BE provision is progressively increased with rising shares of VRES. Giving the regional differences, it should be stressed that the regional context, the relative share of wind and solar PV in the power system and therefore the investigated time horizon are important for defining the role of flexible bioenergy in the years to come.

Keywords: Bioenergy, Flexible energy provision, Wind energy, Solar PV, Residual load

\section{Background}

The shift from a fossil fuel energy system to a low-carbon renewable energy system is vital for a sustainable development in the future. This transformation of our energy system requires a rethinking and redesign of how energy shall be produced and supplied in the future. Within the European Union, a renewable target of $20 \%$ in the final energy consumption by 2020 has been set by the Renewable Energy Directive 2009/28/EC as cornerstone [1]. Recently, the European Commission has stated a new target of at least $27 \%$ of the final energy consumption from renewables (at least $45 \%$ share in the electricity sector) by 2030 as part of the climate and energy goals for 2030 [2]. With an increasing share of renewables in the power sector, a demand for a new energy system design integrating and replacing the different emerging and existing energy sources in an efficient way occurs. Especially, the market integration of intermittent electricity provision by wind and solar power asks for flexible means in the power system in order to facilitate a secure and sustainable energy supply [3].

Strategies, which are currently being discussed for addressing this challenge and thus offsetting the temporal and spatial discrepancy of energy supply and demand, are manifold. The considered flexibility options cover the development of power storage and Power-to-X technologies, expansion of the electricity grid and interconnectors for import and export as well as enabling smart electricity supply (flexible fossil and renewable power plants) and demand side management (DSM). Referring to the latter option, this research focuses on the opportunities and challenges of a flexible power supply based on biomass conversion technologies. The intention is to reveal whether a flexible power generation based on biomass can be an appropriate approach for the system integration of the increasing share of vRES.

Therefore, this study addresses the following research question:

- What impact does a flexible operation of biomass installations has on the integration of renewables in a future solar PV-dominated power system?
To answer this question, we will assess (i) the impact of flexible bioenergy provision on daily variability in residual load (RL) (total load minus feed-in from renewables) as an indicator for system integration of renewables and (ii) the ability of a flexible operation of biomass plants to avoid power production in times of negative residual load (when renewables already cover the power demand).

\section{Scope}

The scope of this paper is the assessment of the role of flexible biomass installations in one of the four German transmission systems (TS) by 2022. Germany has been chosen as case study since it has an ambitious midterm goal of 40 to $45 \%$ by 2025 and a long-term goal of at least $80 \%$ renewables within the electricity system by 2050 [4], starting from a current share of $32.6 \%$ (195.9 billion kWh) in 2015 [5]. Thus, Germany is going to be affected by the stated problem. The intention is to show the impact of flexible bioenergy provision for balancing vRES in Germany in the midterm. This assists in identifying significant aspects and challenges for the electricity system on the road towards an energy supply based on $100 \%$ renewable energy sources.

Moreover, reflecting on the midterm perspective is of particular importance as the role of bioenergy (BE) in the German power system is highly disputed and existing $\mathrm{BE}$ installations as well as future investments in the sector are subject to uncertainty in the national energy policy. The year under consideration (2022) has been chosen in correspondence to the time horizon of the reference scenario considered within the "Network development plan electricity 2012 (NEP 2012)" [6]. The NEP 2012 includes a very comprehensive record on the scenario design for the midterm development of the electricity production in Germany, including a scenario for 2022 which was used for this case study. By choosing the year 2022, we focus on already available technologies and existing plant infrastructure.

Furthermore, the operation of flexible bioenergy facilities can mainly be found in Germany at the moment. This development has been particularly stimulated by 
favourable legislative conditions. Since 2012, the German feed-in tariff system (EEG) provides a bonus payment for a flexible operation of biogas installations. Here, investments in additional infrastructure are promoted which are allowing a demand-oriented electricity production. This policy environment facilitated the development and establishment of flexible biomass conversion facilities. Therefore, the German electricity system has comparatively great wealth of experience in a flexible electricity supply.

Within the German electricity market, we focused on the TransnetBW transmission system as the case study region. As Germany is divided into four transmission systems, the reflection of the transmission system as a whole is rather challenging. Therefore, the TransnetBW transmission system has been chosen as the study area since it shows a high share of solar PV posing specific challenges for balancing RL.

\section{Review of previous studies}

Studies reflecting options for balancing fluctuating electricity feed-in from renewable energy sources have mainly emerged in the last few years. Especially, since the impact of an increasing share of vRES within the European electricity system is being felt, the issue is on the political and research agenda. Although limited in volume, excess power generation from wind and solar has already led to their curtailment what is associated with significant economic losses.

A sound overview of the overall options for vRES integration is provided by the IEA report published in 2014 [7], ranging from system friendly vRES deployment, improved system and market operation and finally new infrastructure like flexible BE.

Many individual studies analyze and discuss the future challenges of large shares of vRES within the future European electricity system [8-11] (overall system approach).

Albrecht et al. [8] investigate the challenge of different instruments to stimulate the long term capacity building of renewable energy installations. They address that there is a need for pull-(RD\&D) as well as for push -factors (production subsidies). A second large topic is that renewable electricity generation will be dominated in the future by solar and wind power [6, 9]. Subsequently, the most challenging issue is balancing these large vRES capacities because their stochastically feedin characteristic does not necessarily match the demand patterns [10-13].
Other studies reflect on the various technology options for a smart integration of vRES [14-18] or they present specific case studies on applying several technologies for balancing variable renewable energy sources in a certain region [19-22]. For example in [18] the possibilities of combined heat and power (CHP) production for balancing large amounts of wind power in Finland were investigated. It was shown that CHPs can contribute to the balancing of vRES, while maintaining high overall efficiency, using adequate amounts of thermal storage capacities to uncouple electrical and thermal generation. Another example is given by [19] where the potential for balancing wind by demand-driven biogas plants for Latvia was investigated. On the level of market and system integration, [20] shows the potential to reshape the recent market design for a better integration of wind power to provide regulating power to balance fluctuations in electricity systems.

The study on hand picks up this last group of specific technological options that facilitate the integration of vRES in a defined transmission system. Here, it particularly relates to the investigations of flexible $\mathrm{BE}[16,17]$ and intends to draw a comparison to the research results of flexible biomass installations in another transmission system [22]. This approach shall assist in deriving general conclusions on the contribution of flexible biomass provision for balancing variable power generation from solar and wind power in the midterm. Compared to most other studies, we are aiming at modelling the specific challenges of flexible $\mathrm{BE}$ in a power system with a higher degree of differentiation between BE conversion technologies (clusters). Here, we focus on the near-to-midterm which limits the technical options for flexible BE but allows us to answer the question of the effectiveness as well as the requirement for flexible $\mathrm{BE}$ in the midterm.

The analysis is based on three different scenarios, which are described in the "Scenario overview" section; the corresponding modelling is presented in the "Methods" section and the modelling results in the "Results and discussion" summarizing section.

\section{Scenario overview}

We define three different scenarios in order to assess the role of bioenergy on the provision of power in the TransnetBW transmission grid in the year 2022. Table 1 gives an overview of the considered scenarios.

As a reference, we use a no bioenergy (NO-BE) scenario, which excludes $\mathrm{BE}$ from the energy mix, assisting

Table 1 Overview of the different scenarios in 2022

\begin{tabular}{llll}
\hline & NO-BE no bioenergy at all & NON-Flex-BE non-flexible bioenergy & Flex-BE flexible bioenergy \\
\hline Installed power from bioenergy plants & - & $639 \mathrm{MW}$ & $985 \mathrm{MW}(+346 \mathrm{MW})$ \\
Annual energy production (AEP) from bioenergy & - & $5.6 \mathrm{TWh} / \mathrm{a}$ & $5.6 \mathrm{TWh} / \mathrm{a}$ \\
\hline
\end{tabular}


in evaluating the impact of bioenergy supply on the investigated transmission system. Among the two bioenergy scenarios, one includes $\mathrm{BE}$ in the form of a nonflexible bioenergy (NON-Flex-BE) provision. Here, a quasi-constant power feed-in of $639 \mathrm{MW}$ from $\mathrm{BE}$ is modelled. Based on [23, 24], we derived annual full load hours and installed capacities and assumed that the $639 \mathrm{MW}$ of installed capacity is operated at rated capacity throughout the whole year. This non-flexible operation has been the predominant type of $\mathrm{BE}$ power provision until the introduction of the bonus payment for a flexible operation of biogas installations in the year 2012. The other scenario covers a flexible BE (Flex-BE) provision. Here, we assume a certain kind of installation of extra power capacity, although the overall BE power production of $5.6 \mathrm{TWh} / \mathrm{a}$ remains unchanged in comparison to the NON-Flex-BE scenario to maintain the comparability of the results (see Table 1 ). The additional $346 \mathrm{MW}$ resulting in a number of assumptions in the way BE plants becomes flexible. First of all, we assume that only some of the existing plants (see shares for the Cluster 1 and Cluster 2 in Table 2) will be upgraded and extended in installed capacity, for example for small plants, the effort would not worth the required investments. For the plants which are upgraded to be operated flexibly, we assume that they double their installed capacity.

For modelling purposes, the portfolio of biomass installations has been grouped into two clusters representing each the dominating bioenergy technologies within Germany. The intention is to reflect on these substantially different technologies in terms of their ability to serve demand-driven electricity supply. Cluster 1 covers wood-based heat and power plants based on condensing technology using steam as well as the organic rankine cycle process. Cluster 2 represents biogas plants and other plants with comparable technologies like CHP units driven by biomethane or vegetable oils.

Based on typical biogas and wood-fired combined heat and power plant (WCHPP), assumptions for the flexible operation for both clusters were made. Here, especially the expansion of the installed capacities as well as storage capacities for intermediate energy, enabling plants to control their feed-in for several hours, was taken into consideration. Hereby, we focused on already available technologies for retrofitting existing plants, as the level of the current incentives of the feed-in tariff system is expected to result in a rather small increase in the total installed capacities in the years to come [23, 25]. Hence, innovative technologies, like multi-stage biogas plant concepts [26-28] or gasification CHPs for solid biomass [29] with larger bandwidth for load changes or spread between minimal and maximal load, are more likely to be realized after the year 2022 .

Cluster 1 is represented by an average WCHPP. These types of plants are to a large extent integrated into combined heat and power (CHP) systems and mostly operated in a heat-driven mode. Nevertheless, these plants also provide a certain kind of flexibility. Even with a non-flexible mode of operation, the installed capacity is significantly larger than the rated power. However, in contrast to biogas installations, these plants are only able to adjust their power output slowly, due to the thermal inertia, caused by the steam generation in a large boiler.

Cluster 2 is represented by an average agricultural biogas plant (ABP). In case of the flexible operation, the installed capacity is more than two times the amount of the rated capacity. This means the plant can run for less than $11 \mathrm{~h}$ in a full load operation each day. Biogas plants are characterized by a high daily flexibility, resting upon an easy to control power output of generator sets and a relatively constant gas production. The constant gas production leads to an inflexibility related to seasonal adaptations in contrast to daily adaptations [30-32]. Table 2 provides an overview on the characteristics of the two clusters.

As the scenario for 2022 depends largely on the nonbioenergy-related elements of the power system, key scenario assumptions are given in Table 3 . Here, the key capacities and energy figures for the different renewable power sources in the TransnetBW grid are given according to the scenario of the NEP for Germany by 2022 [6]. The NEP describes the measures that are required in

Table 2 Overview of typical characteristics and parameters for plants of the bioenergy clusters 1 and 2

\begin{tabular}{llll}
\hline Sample plant characteristics & Unit & Cluster 1 & Cluster 2 \\
\hline Plant type & - & Wood-fired combined heat and & Biogas plant (biogas) \\
& & power plant (solid biomass) & 330 \\
Rated capacity & {$[\mathrm{kW}]$} & 2500 & 430 \\
Installed capacity (inflexible design) & {$[\mathrm{kW}]$} & 4750 & 700 \\
Installed capacity (flexible design) & {$[\mathrm{kW}]$} & 6000 & 75 \\
Share of flexible capacity (flexible design) & {$[\%]$} & 40 & 75 \\
\hline
\end{tabular}


the next decade for designing a German electricity grid that can efficiently integrate the emerging renewable energy sources. Thus, a safe and reliable grid operation can be ensured.

The data of the NEP is chosen as reference for modelling the future development of RES, based on a 2-year time series data (2011/2012, see "Methods" section).

Specific to the TransnetBW transmission grid is the high share of solar PV regarding the projected capacity mix from renewables. sixty-eight percent of the overall projected installed capacity of renewables comes from solar PV, which is expected to provide a $36 \%$ share of the total energy produced from renewables in 2022. River hydro (25\%), bioenergy (23.3\%), wind power (12.1\%) and other renewables (3.7\%) contribute with minor shares to the overall renewable share of $35 \%$ in the region in 2022.

\section{Methods}

This paper is a follow-up on the publication of the 2015 book chapter [22] where a comparable approach was developed and applied to investigate the effects of flexible power generation from bioenergy for the 50 Hertz transmission system in Germany for the years 2011 and 2030. Compared to the book publication, some minor refinements within the modelling have been included. BE technologies are now

Table 3 Scenario framework for the case study including the three scenarios

\begin{tabular}{|c|c|c|}
\hline \multirow[t]{3}{*}{ Energy source } & \multicolumn{2}{|l|}{ Year 2022} \\
\hline & Capacity (CAP) & $\begin{array}{l}\text { Annual energy } \\
\text { production }\end{array}$ \\
\hline & {$[\mathrm{MW}]$} & [TWh/a] \\
\hline Wind & 1900 & 2.9 \\
\hline Solar PV & 8900 & 8.6 \\
\hline River hydro & 1000 & 6.0 \\
\hline Other renewables & 200 & 0.9 \\
\hline \multicolumn{3}{|l|}{ Bioenergy } \\
\hline Scenario NO-BE & 0 & 0 \\
\hline Scenario NON-Flex-BE & 639 & 5.6 \\
\hline Scenario Flex-BE & & - \\
\hline - Flexible solid biomass (cluster 1) & 102 & 0.5 \\
\hline $\begin{array}{l}\text { - Flexible biogas, liquid biofuel } \\
\text { CHP (cluster 2) }\end{array}$ & 530 & 2.2 \\
\hline - Remaining BE must run & 333 & 2.9 \\
\hline Total & & $24^{a}$ \\
\hline
\end{tabular}

${ }^{a}$ Based on the average demand from 2011 to 2012 of 68.4 TWh, capacity for 2011 from NEP 2012 2022B scenario [6], resulting in a REN Share of 27\% in scenario NO-BE and $35 \%$ for NON-Flex-BE and Flex-BE aggregated into two clusters. Moreover, the input data for the investigated TS differs in the investigated time horizon (2022 instead of 2011 and 2030). These differences may lead to limitations in the comparability of the results, which will be explained in greater detail in the "Discussion" section.

\section{Modelling}

The RL is calculated based on time series data (2011-2012) and the installed capacities for 2022, which are provided in Table 3. RL is defined as the total load minus feed-in from wind, solar, hydro and other renewables except of bioenergy. The use of historical feed-in and total load data with its variability over two climate periods (years 2011 and 2012) builds the basis for an extrapolation for RL of the modelling year 2022. This is done by using a normalizing and scaling approach of the feed-in from wind [33] and solar PV [34] that covers the build-up of new wind and solar PV capacities projected for 2022 (see Tafarte 2014 [35]). For river hydro and the category "other renewables", we assume a constant power production over time. The total load data of the TS is likewise provided by the transmission system operator [36].

For the scenario NO-BE, no modelling is applied, as we simply analyze the RL without any feed-in from bioenergy. The key figures of this scenario are presented in Table 5 in the "Results and discussion" section.

For the scenario NON-Flex BE, a constant feed-in of bioenergy $(639 \mathrm{MW})$ is subtracted from the RL of scenario NO-BE, which is equivalent to an AEP from BE (5.6 TWh/a) over the course of 1 year (Eq. 1). No further modelling is applied.

$$
\operatorname{RLB}_{(t) \text { NON-Flex }}=\mathrm{RL}_{(t)}-639 \mathrm{MW}
$$

In the case of the Flex-BE scenario, the power production from the bioenergy plants is modulated in order to offset RL fluctuations. Therefore, an optimization algorithm that minimizes daily RL fluctuations is used [22,37] which is implemented by the modulation factors $m$ added to Eq. 1 . Hence, the installed power generation capacity of the two bioenergy clusters is modulated in power output by the optimization algorithm in order to minimize daily variances in $\mathrm{RL}[22,37,38]$. The algorithm enables bioenergy plants to contribute to use their flexibility in the Flex-BE scenario by shifting power generation from times of lower RL to times of higher RL, thus contributing to the balancing of power supply. 
The operation of cluster 1 and cluster 2 is performed in sequence so that the resulting RL in the Flex-BE scenario is $R L B E_{\text {flex combined }}$, calculated from $R L B E_{\text {flex cluster }}$

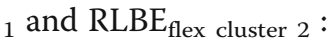

$$
\operatorname{RLBE}_{(t) \text { flex cluster } 1}=\mathrm{RL}_{(t)}-m_{(t) \text { cluster } 1} * \mathrm{CAP}_{\text {cluster } 1}
$$

$$
\begin{aligned}
\operatorname{RLBE}_{(t) \text { flex combined }}= & \operatorname{RLBE}_{(t) \text { flex cluster 1 }}-m_{(t) \text { cluster } 2} \\
& * \mathrm{CAP}_{\text {cluster } 2}
\end{aligned}
$$

$$
\begin{aligned}
& \min \text { variances }\left(m_{(t) \text { cluster } 1} ; m_{(t) \text { cluster 2 }}\right) \\
&=\sum_{t=1}^{24} \operatorname{RLBE}_{(t) \text { flex combined }}
\end{aligned}
$$

The daily "variances" as a function of the two modulation factors " $m(t)$ cluster 1 " and " $m(t)$ cluster 2" (Eqs. 2 and 3 ) are subject to minimization (Eq. 4) so that the modulation of power output of the two clusters is optimized in order to reduce the observed daily variances in RL. Key technical parameters of the two different clusters are provided in Table 4.

The parameterization of the bioenergy plant clusters, in particular, the annual electricity production and initially installed capacities, is derived from the current inventory of bioenergy facilities installed in Germany.

The operation of the two bioenergy technology clusters is performed in sequence so that the temporal more dynamic technologies of cluster 2 (biogas, liquid biofuel CHP) come second after the less dynamic cluster 1 (solid biomass). This is done to ensure that both clusters with their specific characteristic are not operated in a conflicting way but rather complementary. The parameterization and operation of both technology clusters are explained in the following:

Cluster 1 (solid biomass plants): Firstly, the combined installed capacity from solid biomass plants is modulated from 0.5 to 1.2 in 2-h time steps for each day of the 2-year time series, meaning that the combined installed capacity from cluster 1 is multiplied by the modulation factor $m$ and subtracted from the RL time series. The modulation factor of 0.5 is applied as the minimum modulation factor of the combined installed capacities, as the current heat demand from CHP production and the conversion technology do not allow for a power output below 0.5 or $50 \%$ of the rated power. Additionally, as there is a lower heat demand in summer, the daily energy production during the summer time is reduced by $66 \%$ compared to the operation during winter.

Cluster 2 (biogas, liquid biofuel CHP): The combined installed capacity from the plants of cluster 2 is modulated from 0 to 1 but on the basis of the RL remaining after the feed-in from cluster 1 . The installed capacity of cluster 2 already includes the upgrading of the plant with additional installed power generation sets. Lower average power demand on weekends is taken into account so that daily power production is reduced by $38 \%$ accordingly. No seasonal adaptation of the plants is modelled in cluster 2 .

\section{Results and discussion}

Table 5 gives an overview over key results from the modelling of flexible bioenergy in the TransnetBW transmission grid for the year 2022.

The modelling results show how flexible production of bioenergy contributes to reduce variability of RL on a daily basis and to what extent maximal and minimal RL was affected in the three scenarios throughout the 2year time series.

Scenario "NO-BE", which excludes any use of bioenergy from the power system, provides the baseline for a comparison to the scenarios "NON-Flex-BE" as

\begin{tabular}{|c|c|c|}
\hline & \multicolumn{2}{|l|}{ Bioenergy technologies } \\
\hline & Cluster 1 (solid biomass) & Cluster 2 (biogas, liquid biofuel CHP) \\
\hline Modulation of power output & $m_{(t)}$ cluster $1=0.5-1.2$ in 2-h time steps & $m_{(t)}$ cluster $2=0-1.0$ in 1-h time steps \\
\hline \multirow[t]{3}{*}{ Operational constraints } & - Constant daily energy production & - Constant daily energy production \\
\hline & $\begin{array}{l}\text { - No storage limitations for input materials } \\
\text { affecting operation }\end{array}$ & $\begin{array}{l}\text { - On-site biogas storage equivalent to } 12-24 \mathrm{~h} \\
\text { in biogas production }\end{array}$ \\
\hline & $\begin{array}{l}\text { - Reduced daily production (-66\%) during } \\
\text { summer from April to October }\end{array}$ & $\begin{array}{l}\text { - Reduced bioenergy production (-38\%) on } \\
\text { weekends assuming feeding management }\end{array}$ \\
\hline Energy production & $\begin{array}{l}\text { Annual energy production (AEP) remains } \\
\text { constant for either non-flexible or flexible } \\
\text { operation. AEP from biomass in } 2022 \text { taken } \\
\text { from [NEP 2022B] }\end{array}$ & \\
\hline
\end{tabular}
well as "Flex-BE".

The contribution of bioenergy (8\%) to the overall power consumption in the considered transmission system is

Table 4 Technical parameters for the flexible operation from cluster 1 and cluster 2 bioenergy plants 
Table 5 Overview of key results from simulated flexible and non-flexible bioenergy power generation in the case study

\begin{tabular}{|c|c|c|c|}
\hline & \multicolumn{3}{|l|}{ Year 2022} \\
\hline & NO-BE & NON-Flex-BE & Flex-BE \\
\hline Renewable share (REN share) & $\begin{array}{l}26.8 \% \\
\text { (other renewables) }\end{array}$ & $\begin{array}{l}\text { 34.9\% (other renewables + } \\
\text { non-flexible bioenergy) }\end{array}$ & $\begin{array}{l}35.0 \% \text { (other renewables }+ \\
\text { flexible bioenergy) }\end{array}$ \\
\hline Variance in daily residual load & - & $100 \%$ & $70 \%$ (reduced by $30 \%{ }^{a}$ ) \\
\hline Maximum positive RL (deficit power) & $10,440 \mathrm{MW}$ & 9801 MW (100\%) & $9458 \mathrm{MW}$ (reduced by $4 \%^{\mathrm{a}}$ ) \\
\hline Minimum negative RL (excess power) & -1965 MW & - 2604 MW (100\%) & - 2362 MW (reduced by $11 \%^{\mathrm{a}}$ ) \\
\hline Hours of negative RL & $42 \mathrm{~h} / \mathrm{a}$ & $98 \mathrm{~h} / \mathrm{a}$ & $70 \mathrm{~h} / \mathrm{a}$ \\
\hline $\begin{array}{l}\text { BE power production in times of } \\
\text { negative } R L\end{array}$ & - & $44.1 \mathrm{GWh} / \mathrm{a}$ & $26.5 \mathrm{GWh} / \mathrm{a}$ (reduced by 40\%) \\
\hline $\begin{array}{l}\text { Avoided BE power production in times } \\
\text { of negative RL }\end{array}$ & - & - & $17.6 \mathrm{GWh} / \mathrm{a}$ \\
\hline
\end{tabular}

apercentages compared to "non-flexible" values

significant and reflects the third major renewable energy source after solar PV (13\%) and river hydro (9\%). Without bioenergy at all, the overall REN share reaches only $26.8 \%$ in the NO-BE scenario compared to around $35 \%$ in the two scenarios including bioenergy: a drop of about one fourth of the overall renewable energy production in 2022.

The average daily variance of the RL is reduced by $30 \%$ in the Flex-BE scenario compared to that of the NON-Flex-BE scenario, which is the primary target of the flexible BE modelled in this study. Maximum RL was likewise reduced by $4 \%$ and minimal RL by $11 \%$ for the Flex-BE scenario.

The REN share for the NON-Flex-BE and the Flex-BE scenario shows hardly any differences. Only a small amount of energy is produced from bioenergy in times of negative RL. In the NO-BE scenario, only $42 \mathrm{~h}$ of negative RL is registered during the 2-year time series. In the NON-Flex-BE scenario, this number is increased to $98 \mathrm{~h}$ as, additionally, the constant feed-in of $639 \mathrm{MW}$ from non-flexible $B E$ is fed into the grid. With a flexible operation of $\mathrm{BE}$, the number of hours is reduced to $70 \mathrm{~h}$ as power production had been shifted into times of positive RL. Any production of bioenergy in the Flex-BE scenario at times of negative $R L$ is due to operational constraints forcing bioenergy plants even in the flexible operation to continue to produce power (see Table 5). This translates into a reduction of $\mathrm{BE}$ produced during times of negative RL of $40 \%$, equivalent to $17.6 \mathrm{GWh} / \mathrm{a}$. Compared to the overall $\mathrm{BE}$ of $5.6 \mathrm{TWh} / \mathrm{a}$ available in the study area, the avoided production of $\mathrm{BE}$ in times of negative RL is negligible with $0.3 \%$.

A detailed analysis of the temporal operation pattern shows how the flexible bioenergy plants adapt to fluctuations in RL. With RL, the result of the total grid load minus feed-in from renewables, characteristic patterns of load and feed-in from renewables can be identified in the operational patterns of flexible bioenergy provision.
Figure 1 gives an example of how flexible operation is affected by these patterns.

The high feed-in from solar PV during a typical summer time load and feed-in situation leads to a low utilization of flexible bioenergy power production around noon. Modest load and high feed-in from solar PV results in a situation, in which bioenergy plants stop producing electricity and production is instead shifted into morning and evening hours of the day, when higher load is not offset by solar PV production.

When averaging the modulation factors for each of the $24 \mathrm{~h}$ of the day over the course of the 2-year time series and differentiating in winter and summer time, the seasonal differences in the daily modulation pattern of power output from cluster 2 can be mapped to cover the full 2-year time series and empirically underline the typical patterns shown in Fig. 1. These seasonal differences in the daily modulation pattern in the power output of cluster 2 (biogas plants and liquid CHP plants) are depicted in Fig. 2. In both seasons, summer and winter, a two-peak daily modulation of the cluster is observed, with a primary peak in the evening and a smaller peak in morning hours. This is to a large extent caused by both patterns of load profiles as well as feed-in patterns from vRES, especially from solar PV. In summer time, the very low average modulation of flexible $\mathrm{BE}$ during noon and a distinct gradient towards the evening peak is a result of this interplay of load profiles and feed-in from solar PV in the study area.

A comparison of average daily profiles of the RL of the NO-BE and the Flex-BE scenario is shown in the following Fig. 3, again differentiated for winter and summer time. First, it can be identified that summer time RL is on average lower than in winter time. Furthermore, the minimum of average RL occurs during midday during summer time, which is again an indicator for a strong influence of the significant installations of solar PV capacities in the study area. 


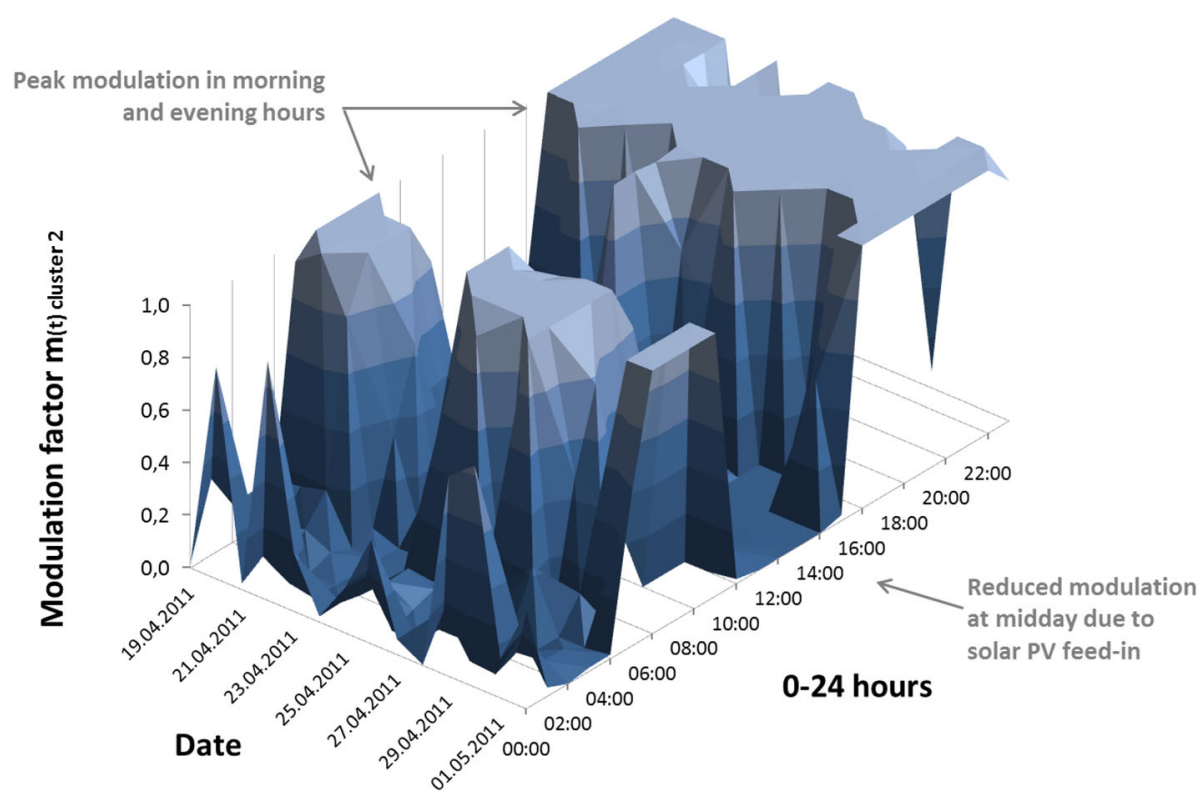

Fig. 1 Typical example for the modulation of power generation from cluster 2 during several days in spring time

In line with the modulation of flexible bioenergy generation shown in Fig. 3, the flexibility is used primarily in hours of high RL so that the daily variance of RL is minimized. The resulting average RL after flexible power generation (dashed line in Fig. 3) is therefore showing a reduction in the morning and evening peaks of the RL, whereas, for example during midday minimum RL situations, the lower average modulation leads to a comparably lower reduction in RL.

The following Fig. 4 depicts the residual load duration curve (RLDC) of the NO-BE, the NON-Flex-BE and the
Flex-BE scenarios. Ordering the RL time series values of the 2-year time series in a descending order creates the duration curves. The highest RL value is located on the very left of the resulting graph and the lowest value on the right side.

Figure 4 shows the duration curves for the 2-year time series used for this study. For the NON-Flex-BE scenario, the duration curve is a simple parallel shift of the RL original duration curve, as a constant $639 \mathrm{MW}$ is subtracted in every hour of the time series. This reduces the maximum RL as well as the minimum RL accordingly, as

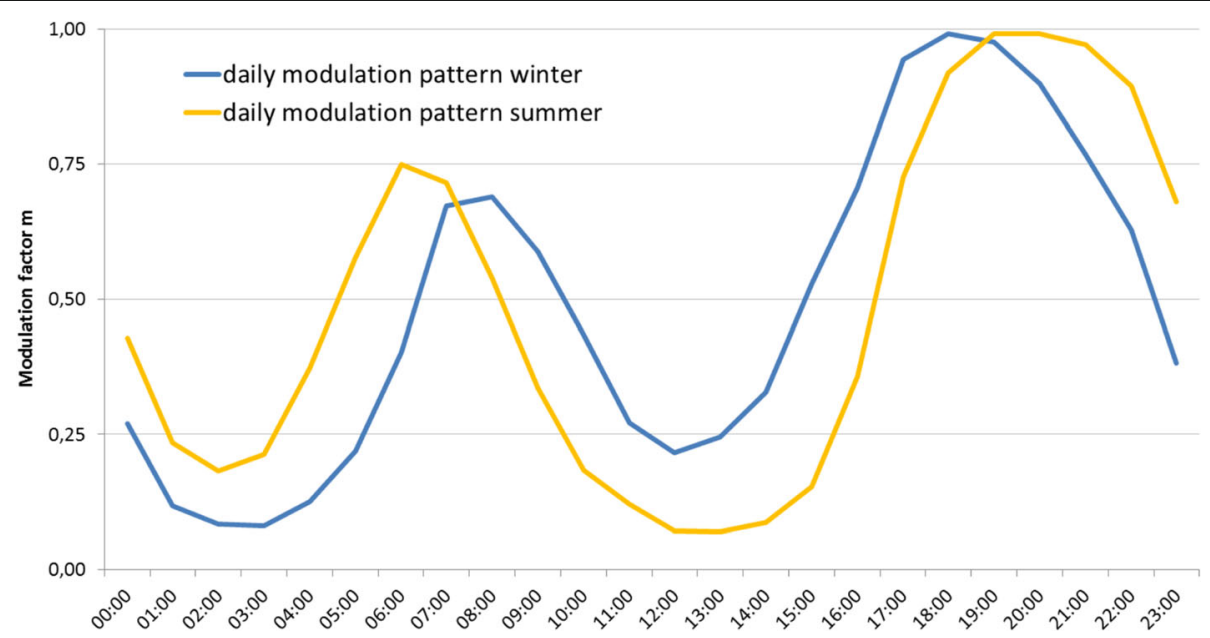

Fig. 2 Average modulation of cluster 2 (biogas plants and liquid CHP plants) over the course of the $24 \mathrm{~h}$ of the day, differentiated for winter and summer time. (Note the typical reduction of modulation at noon, especially pronounced in the graph depicting summer time modulation, caused by high solar PV feed-in; Additionally the earlier and later modulation peak during summer time compared to winter time) 


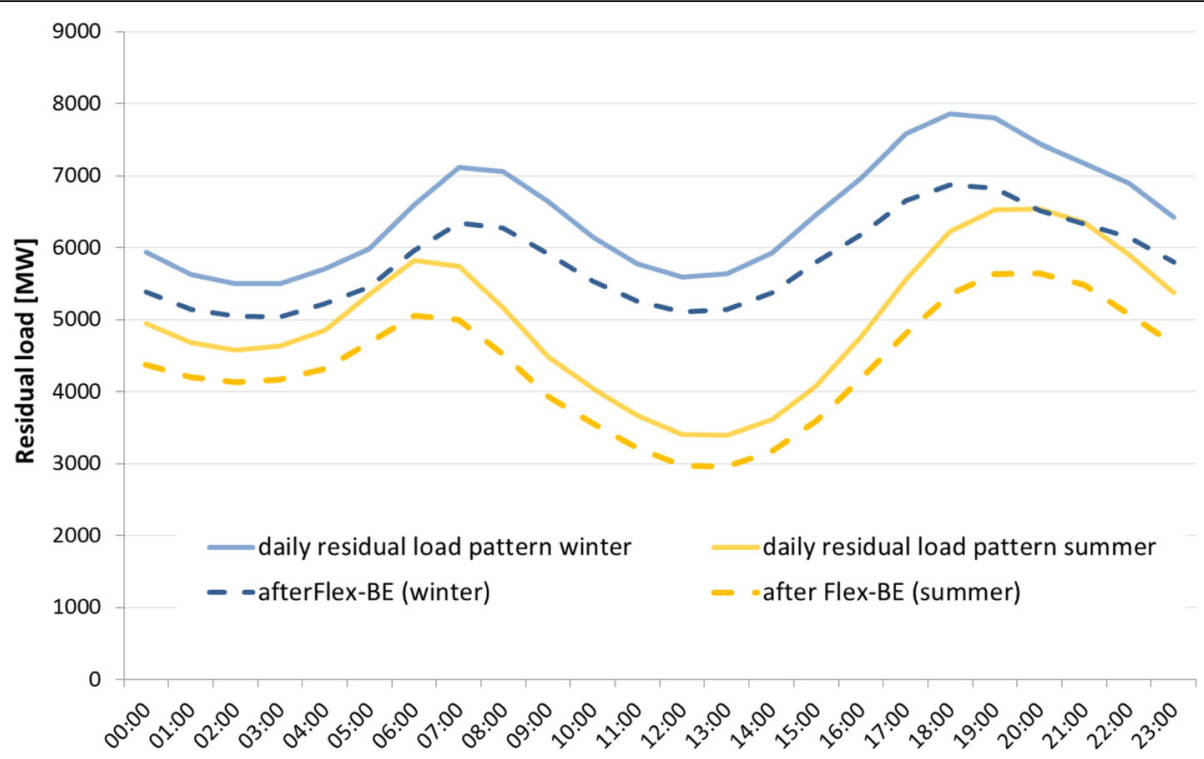

Fig. 3 Daily residual load before and after flexible power generation from biomass, differentiated for winter and summer time. (Note the reduced amplitude in average daily RL after flexible bioenergy power generation and the typical reduction of RL at noon in summer time which is partially caused by high solar PV feed-in)

already given in Table 5. The duration curve of the Flex$\mathrm{BE}$ case is instead showing a slightly different form. As given in Table 5, the extreme values of maximum RL and minimum RL are improved with flexible operation of bioenergy plants in the modelled set-up. The reduction of the maximum RL is enabling a potential reduction in non-fluctuating plant capacity, which is currently mostly driven by fossil fuels and pumped hydro storage (PHS). The flexible operation mode enables a limited shift of power production (area between solid lines of the RL and shifting reflected by the arrow included in the figure) from times of low RL on the right side of the duration curve to times of high RL on the left. Furthermore, in the midrange of the RLDC, a slightly less pronounced declination of the curve can be identified (compare to [39]).

Apparent in the graphic as well as in Table 4 is the fact that RL in 2022 shows only marginal times in which RL for the grid area becomes negative $(98 \mathrm{~h} / \mathrm{a}$ in the NONFlex BE scenario and $70 \mathrm{~h} / \mathrm{a}$ in the Flex-BE scenario) or, in other words, times in which renewable production is greater than the total grid load. Accordingly, flexible operation of bioenergy can do little to avoid excess energy

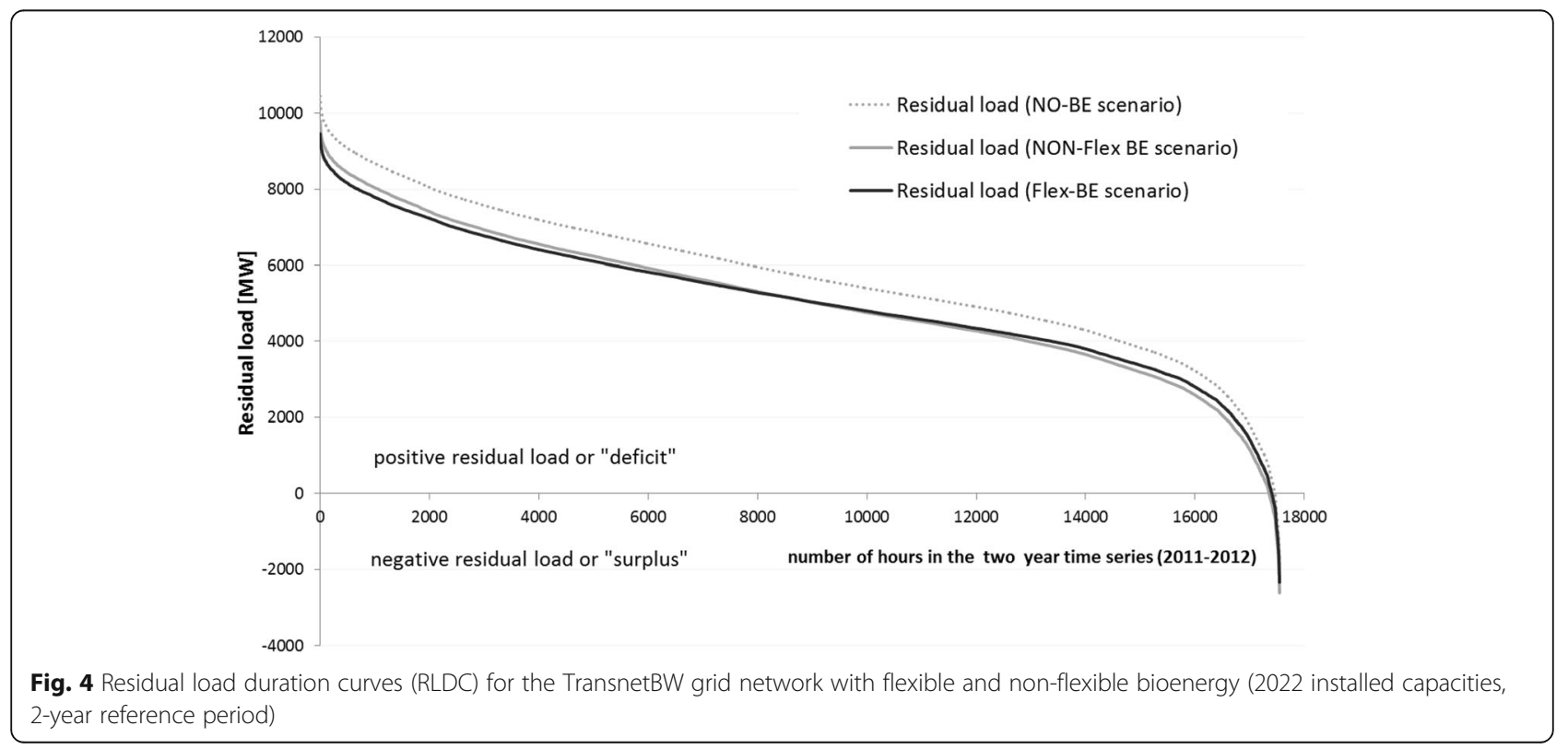


production by shifting bioenergy production into times of positive RL in this 2022 scenario, as basically the amount of vRES in 2022 and the REN share of only $35 \%$ are too low.

\section{Discussion}

In this study, we modelled flexible power provision from bioenergy (BE) for the year 2022 in the TransnetBW transmission system (TS) in Germany. Three scenarios were studied. The NO-BE scenario excluded the utilization of $\mathrm{BE}$ in the energy mix and served as a reference case. The NON-Flex-BE scenario investigated the effect of a constant production of $\mathrm{BE}$ as it has been the case for most BE power plants in recent years. The Flex-BE scenario included a modelling of a flexible BE provision. The BE plants in the Flex-BE scenario were grouped into two different technology clusters and these clusters were modelled in sequence using a rolling optimization of a 24$\mathrm{h}$ time horizon with the objective function of a minimized daily variance of RL fluctuations.

In line with existing publications $[15,17,22,40]$, the results from this case study underline the principal usefulness and functionality of flexible BE in power systems with high shares of vRES. Compared to a similar study for a different transmission system $50 \mathrm{~Hz}$ in Germany for the time horizon 2011 and 2030 [22], the results of the study on hand show similarities as well as some significant differences in the effect of a flexible operation of biomass installations on the power system. Due to the fact that the REN share in the TransnetBW TS for the year 2022 (35\%) is comparable to the REN share in the $50 \mathrm{~Hz}$ TS in $2011(36 \%)$, these two time horizons allow for an adequate comparison of the two studies. The relative share of $\mathrm{BE}$ which is avoided to be produced in times of negative RL is similar in both cases, but the minimization of daily variances as the objective function of the modelling was achieved to a higher degree in the $50 \mathrm{~Hz}$ TS $(-56 \%$ relative to the NONFlex scenario) compared to that in the TransnetBW TS $(-30 \%$ relative to the NON-Flex scenario). Either it can be argued that this is the result of a higher relative share in installed power and generated energy from bioenergy for the $50 \mathrm{~Hz}$ TS, which allows for a greater reduction in $\mathrm{RL}$ variances. Or it is likewise plausible that this is caused by the higher relative share of solar PV in the TransnetBW TS within the overall REN share, as the high variability of solar PV feed-in leads to a higher variability in RL that cannot be fully compensated by flexible BE provision. An indepth investigation for an explanation of these findings is needed to identify how flexible $\mathrm{BE}$ adapts to different scenario settings.

Another indicator for the usefulness of flexible $\mathrm{BE}$ is the fact that the increased installed capacities from $\mathrm{BE}$
(343 MW) in the Flex-BE scenario were fully utilized to reduce the maximum $\mathrm{RL}$ over the course of the 2-year time series data.

The amount of avoided BE production (17.6 GWh/a or $0.3 \%$ of annual $\mathrm{BE}$ ) in times of negative RL can almost be neglected for the 35\% REN share in the Flex-BE scenario of the TransnetBW TS in 2022. So, although today's technical concepts for flexible BE allow for a good adaptation to the vRES feed-in patterns for 2022 in the TransnetBW TS, the limited overall amount of excess energy from renewables is indicating that there is little requirement for flexibility to avoid excess energy in the near-term. This is largely due to the modest REN share of the TransnetBW TS in 2022.

\section{Conclusions}

We conclude that operating biomass installations in a flexible manner effectively reduce the maximum RL values as well as RL fluctuations on a daily basis in a transmission system. The additionally installed capacities in the Flex-BE scenario have been fully utilized in the modelling to reduce maximum RL over the course of the 2-year time series. Hence, the technical concepts for a flexible power provision proved to be effective with regard to their contribution to one aspect of power system functionality and power supply security.

In contrast to the other German transmission systems, the overall REN share is fairly low within the investigated TransnetBW TS and the projections (35\% in 2022) revealed that the REN share continues to lack behind the national REN targets for Germany. As a consequence, the effect on avoided BE power production in times of negative RL is negligible in the calculated scenario, as REN shares are too low to result in a significant share of BE being produced in times of negative RL. So, next to being a future flexibility option, the contribution of $\mathrm{BE}$ with a $23.3 \%$ share within the renewable mix remains a priority in the coming years for the TransnetBW TS in order to achieve the set renewable targets. Consequently, for regions with a low REN share in power supply and a reduced demand for flexibility options, we suggest that $\mathrm{BE}$ should primarily be utilized in the most efficient way in order to maximize its contribution to the REN share in these regions. Maintaining a high efficiency in BE power production and utilization, for example through a combined heat and power production mode, is therefore one crucial element for the $\mathrm{BE}$ utilization in the near-term.

Efficiency should be the top priority until the demand for flexible $\mathrm{BE}$ provision is progressively increased with rising overall REN shares and vRES shares in power supply. Giving the regional differences regarding this aspect, it should be stressed that the regional context, the relative share of wind and solar PV in the power system and 
therefore the investigated time horizon are important for defining the role of flexible $\mathrm{BE}$ in the years to come. So that for this case study region in the near-term outlook for 2022, the largely undebated potential for flexible BE as a flexible asset in future power systems with high shares of vRES $[17,41]$ is not immediately required on a regional perspective for a region with a low overall REN share as investigated in this case study.

The results of the study highlight that further research on the interplay of various integration options and scenario settings is crucial in order to assess the effect of flexible $\mathrm{BE}$ on future power supply systems with growing shares of fluctuating renewables. And it must be pointed out that the full set of flexibility options and their interplay has not been modelled and only the interplays of total load, feed-in from renewables and flexibility of BE in the modelled setup were investigated, what is certainly a limitation to the transferability of the presented results. Furthermore, must-run capacities from thermal power stations and interconnectors, which may significantly influence the effects of a flexible operation of biomass installations on the power system, have not been included in the presented modelling.

\begin{abstract}
Abbreviations
ABP: Agricultural biogas plant; AEP: Annual energy production; BE: Bioenergy; CHP: Combined heat and power; Flex-BE: Flexible bioenergy provision; NOBE: No bioenergy scenario; NON-Flex-BE: Non-flexible bioenergy provision; PHS: Pumped hydro storage; REN share: Renewable share; RL: Residual load; RLDC: Residual load duration curve; Solar PV: Solar photovoltaics; TS: Transmission system; TSO: Transmission system operator; WCHPP: Wood-fired combined heat and power plant
\end{abstract}

\section{Acknowledgements}

This work was funded by the Helmholtz Association of German Research Centers within the project "Biomass and Bioenergy Systems" and supported by the Helmholtz Impulse and Networking Fund, the Helmholtz Interdisciplinary Graduate School for Environmental Research (HIGRADE) as well as the German ministry for nutrition and agriculture. We would like to thank the transmission system operator TransnetBW GmbH for providing the crucial time series data used in this article.

\section{Authors' contributions}

PT carried out the data collection, preparation and processing and the major parts modelling and contributed to the results, discussion and conclusion section as well as to the overall study design. $\mathrm{CH}$ carried out the introduction section and contributed to the discussion and conclusion section as well as to the overall study design. MD provided the bioenergy plant clustering in the modelling section. DT contributed to the discussion and conclusion section as well as to the overall study design. All authors read and approved the final manuscript.

\section{Competing interests}

The authors declare that they have no competing interests.

\section{Author details}

${ }^{1}$ Helmholtz Centre for Environmental Research - UFZ, Permoser Straße 15, 04318 Leipzig, Germany. ${ }^{2}$ Deutsches Biomasseforschungszentrum gGmbH DBFZ, Torgauer Straße 116, 04347 Leipzig, Germany.
Received: 28 April 2016 Accepted: 1 February 2017

Published online: 13 February 2017

\section{References}

1. Council EPa (2009) Directive 2009/28/EC of the European Parliament and of the Council of 23 April 2009 on the promotion of the use of energy from renewable sources and amending and subsequently repealing Directives 2001/77/EC and 2003/30/EC

2. Commission E. A policy framework for climate and energy in the period from 2020 to 2030. COM(2014) 15 final 2014

3. Commission E. Energy Union Package. A framework strategy for a resilient energy union with a forward-looking climate change policy. COM(2015) 80 final 2015

4. Gesetz für den Ausbau erneuerbarer Energien (Erneuerbare-EnergienGesetz - EEG 2014). 2014

5. (AGEE-Stat) WGoRE-S (2016) Development of renewable energy sources in Germany 2015

6. NEP. Netzentwicklungsplan Strom 2012. 2.Überarbeiteter Entwurf der Übertragungsnetzbetreiber. 50Hertz, Amprion, TenneTTSO, TransnetBW. 50Hertz, Amprion, TenneT TSO, TransnetBW; 2012

7. IEA (2014) The power of transformation: wind, sun and the economics of flexible power systems. International Energy Agency (IEA)., p 238

8. Albrecht J, Laleman R, Vulsteke E (2015) Balancing demand-pull and supplypush measures to support renewable electricity in Europe. Renew Sust Energ Rev 49:267-277

9. Lunz B, Stöcker P, Eckstein S, Nebel A, Samadi S, Erlach B et al (2016) Scenario-based comparative assessment of potential future electricity systems - a new methodological approach using Germany in 2050 as an example. Appl Energy 171:555-580

10. Spiecker S, Weber C (2014) The future of the European electricity system and the impact of fluctuating renewable energy — a scenario analysis. Energy Policy 65:185-197

11. Batalla-Bejerano J, Trujillo-Baute E (2016) Impacts of intermittent renewable generation on electricity system costs. Energy Policy 94:411-422.

12. Schlachtberger DP, Becker S, Schramm S, Greiner M (2016) Backup flexibility classes in emerging large-scale renewable electricity systems. Energy Convers Manag 125:336-346

13. Huber M, Dimkova D, Hamacher T (2014) Integration of wind and solar power in Europe: assessment of flexibility requirements. Energy 69:236-246

14. Lund PD, Lindgren J, Mikkola J, Salpakari J (2015) Review of energy system flexibility measures to enable high levels of variable renewable electricity. Renew Sust Energ Rev 45:785-807

15. Schill W-P (2014) Residual load, renewable surplus generation and storage requirements in Germany. Energy Policy 73:65-79

16. Thran D, Dotzauer M, Lenz V, Liebetrau J, Ortwein A (2015) Flexible bioenergy supply for balancing fluctuating renewables in the heat and power sector-a review of technologies and concepts. Energy, Sustainability and Society 5(1):35

17. Szarka N, Scholwin F, Trommler M, Fabian Jacobi H, Eichhorn M, Ortwein A et al (2013) A novel role for bioenergy: a flexible, demand-oriented power supply. Energy 61:18-26

18. Rinne S, Syri S (2015) The possibilities of combined heat and power production balancing large amounts of wind power in Finland. Energy 82:1034-1046

19. Dzene I, Romagnoli F. Assessment of the potential for balancing wind power supply with biogas plants in Latvia. International Scientific Conference "Environmental and Climate Technologies", CONECT 2014. 2015;72:250-5

20. Sorknæs P, Andersen AN, Tang J, Strøm S. Market integration of wind power in electricity system balancing. Future Energy Systems and Market Integration of Wind Power. 2013;1:174-80

21. Jentsch M, Trost T, Sterner M. Optimal use of power-to-gas energy storage systems in an $85 \%$ renewable energy scenario. 8th International Renewable Energy Storage Conference and Exhibition (IRES 2013). 2014;46:254-61

22. Tafarte P, Das S, Eichhorn M, Dotzauer M, Thrän D (2015) The potential of flexible power generation from biomass: a case study for a German region. In: Smart bioenergy: technologies and concepts for a more flexible bioenergy provision in future energy systems., pp 141-59

23. Scheftelowitz M, Thrän D, Hennig C, Krautz A, Lenz V, Liebetrau J, et al. DBFZ Report Nr. 21 - Entwicklung der Förderung der Stromerzeugung aus Biomasse im Rahmen des EEG. Leipzig: DBFZ Deutsches Biomasseforschungszentrum gemeinnützige GmbH, Prof. Dr. mont. Michael Nelles (Hg.), 2014 
24. TransnetBW. EEG-Anlagenstammdaten. available online: https://www. transnetbw.de/de/eeg-kwkg/eeg/eeg-jahresabrechnung. Accessed 07 Feb 2017.

25. Thrän D, Scheftelowitz M (2016) Biomasse im EEG 2016 - Hintergrundpapier zur Situation der Bestandsanlagen in den verschiedenen Bundesländern. DBFZ Deutsches Biomasseforschungszentrum gemeinnützige $\mathrm{GmbH}$

26. Mauky E, Jacobi H, Liebetrau J, Nelles M (2015) Flexible biogas production for demand-driven energy supply-feeding strategies and types of substrates. Bioresour Technol 178:262-269

27. Grossmann J, Hilse H. Neue Systeme der Biogaserzeugung: Zweistufige Trocken-Nass-Vergärung mit getrennter Hydrolyse - das GICON-Verfahren. Conference I-ALB-Kongress 2008, vol. 53

28. Ganagin W, Loewe K, Loewen A, Wallmann R. (2012) Flexible Biogasproduktion zur Erzeugung von Spitzenlaststrom. Tagungsband Jahrestagung Fachverband Biogas e.V

29. Molino A, Chianese S, Musmarra D (2016) Biomass gasification technology: the state of the art overview. J Energy Chem 25:10-25

30. Hahn H, Krautkremer B, Hartmann K, Wachendorf M (2014) Review of concepts for a demand-driven biogas supply for flexible power generation. Renew Sustain Energy Rev 29:383-393

31. Mauky E, Jacobi HF, Liebetrau J, Nelles M (2015) Flexible biogas production for demand-driven energy supply-feeding strategies and types of substrates. Bioresource Technology 178:262-269

32. Elasri O, El amin Afilal M. (2016) Potential for biogas production from the anaerobic digestion of chicken droppings in Morocco. Int J Recycling Org Waste Agric 5:195-204

33. TransnetBW. Wind infeed. available online: https://www.transnetbw.com/en/ transparency/market-data/key-figures. Accessed 7 Feb 2017

34. TransnetBW. Photovoltaic Infeed. available online: https://www.transnetbw. com/en/transparency/market-data/key-figures. Accessed 7 Feb 2017

35. Tafarte P, Das S, Eichhorn M, Thrän D (2014) Small adaptations, big impacts: options for an optimized mix of variable renewable energy sources. Energy 72:80-92

36. TransnetBW. total load. available online: https://www.transnetbw.com/en/ transparency/market-data/key-figures. Accessed 7 Feb 2017

37. Fraunhofer_IWES (2014) Geschäftsmodell Energiewende - Eine Antwort auf das "die-Kosten-der-Energiewende"-Argument. Fraunhofer_IWES, Freiburg

38. Schreiber M. (2012) Bewertungskriterien einer optimierten Energieversorgung regionaler Verbünde mit hohen Anteilen erneuerbarer Erzeugung. Z Energiewirtsch 36:257-265

39. Ueckerdt F, Hirth L, Luderer G, Edenhofer O (2013) System LCOE: what are the costs of variable renewables? Energy 63:61-75

40. Sterner M. Bioenergy and renewable power methane in integrated $100 \%$ renewable energy systems_limiting global warming by transforming energy systems. available online: http://www.upress.uni-kassel.de/katalog/ Download.php?|SBN=978-3-89958-798-2\&type=pdf-f. Accessed 12 Dec 2016

41. Achner S, Brühl S, Krzikalla N (2013) Möglichkeiten zum Ausgleich fluktuierender Einspeisungen aus Erneuerbaren Energien., BET Büro für Energiewirtschaft und technische Planung $\mathrm{GmbH}$

\section{Submit your manuscript to a SpringerOpen ${ }^{\circ}$ journal and benefit from:}

- Convenient online submission

- Rigorous peer review

- Immediate publication on acceptance

- Open access: articles freely available online

- High visibility within the field

- Retaining the copyright to your article 